\title{
Reversal Effect of Coriandrum sativum Leaves Extract on Learning and Memory Deficits Induced by Epilepsy in Male Rat
}

\author{
Mahmoud Elahdadi-Salmani ${ }^{1,} ;$; Mahdi Khorshidi ${ }^{1}$; Jamile Ozbaki ${ }^{1}$ \\ ${ }^{1}$ Institute of Biological Sciences, Faculty of Biology, Damghan University, Damghan, Iran \\ *Corresponding author: Mahmoud Elahdadi-Salmani, E-mail: elahdadi@du.ac.ir \\ Received: January 15, 2014; Accepted: February 28, 2014
}

\begin{abstract}
Background: The extract of Coriandrum Sativum L., commonly known as coriander, belonging to the Apiaceae family (Umbelliferae), is cultivated throughout the world for its nutritional value. C. sativum was shown to enhance cognitive performance and recover memory deficit. On the other hand, epilepsy induces cognitive disorders; learning and memory deficits in different animal models. Thus, the present study was undertaken to investigate the effects of $C$. sativum on water maze learning and memory of epileptic rats.

Materials and Methods: In this experimental study, C. sativum extract was injected intraperitoneally for 7 consecutive days to experimental animals. Pilocarpine was administered (i.p.) to induce epileptic convulsions. Morris water maze (MWM) apparatus served as the behavioral model for testing spatial learning and memory. Latency to locate the platform, swimming distance and velocity were employed as variables in acquisition and probe trials, while crossing and proximity were only used in probe test.

Results: The latency and distance to reach the hidden platform increased in pilocarpine treated rats. C. sativum extract decreased the latency and distance to platform compared with control and more prominently compared with epileptic group. Pilocarpine convulsions increased the platform location latency, but C. sativum extract did not reverse this seizure induced latency increase. Conversely, $C$. sativum extract reversed the seizure induced proximity increase.
\end{abstract}

Conclusion: C. sativum extract may be a useful remedy in the management of epilepsy induced learning and memory impairments.

Keywords:Epilepsy; Coriandrum sativum; Maze Learning; Memory

\section{Introduction}

Epilepsy is a chronic neurological disorder characterized by unprovoked seizures, as a result of excessive, synchronous discharge of cerebral neurons. Complaints of memory impairment are common in epilepsy, and verbal memory deficits have been reported in association with left hippocampal sclerosis $(1,2)$. Seizure induced cognitive and behavioral impairments (3-6) can have a great impact on daily life (7-11). Cognitive deficits represent a serious neuropsychological problem in people suffering from temporal lobe epilepsy (12). Memory deficit due to seizures are not ameliorated with antiepileptic drugs treatment (13) and they may even enhance the reduction. An early and persistent deficit of spatial memory during epileptogenesis was demonstrated in pilocarpine model of temporal lobe epilepsy (14-16). Further, pentylenetetrazol kindled seizures produced a profound decrease in learning and memory of rat in Morris water maze test $(17,18)$. However, kainatetreated rats revealed less impaired spatial memory (19).

Coriander (C. sativum) is a plant, that both its leaves and seeds are grown as spice group all over the world. The C. sativum extract is mainly composed of aromatic acids containing 2-decenoic acid, tetradecenoic acid, capric acid, undecyl alcohol, tridecanoic acid and undecanoic acid (20). C. sativum improves blood circulation to the brain, and recover memory capabilities. It has hypotensive, hypolipidimic, hypoglycemic, anticancer, antioxidant and anti-inflammation properties $(21,22)$. Corianders also used as anti-edemic, antiseptic, emmenagogue, antidiabetic, anti-hypertensive, lipolytic, myo-relaxant, and nerve-soothing properties (23). More specific, its leaves contain proteins, traces of fats, minerals (like calcium, phosphorus, and iron), carotene, fiber and carbohydrates, and stimulate the appetite and its fresh juice is recommended for patients suffering from vitamin A, B and $C$ deficiencies and also for the relief of anxiety and insomnia (24). C. sativum, when fed along with normal diets for 45 days, improved memory of rats (25). Further, C. sativum were useful in reversing Alzheimer induced learning deficit (26). Efforts to control seizure-induced cognitive disorders could significantly improve the quality of life for many epileptic patients. Therefore, the present investigation aims to clarify the role of $C$. sativum aqueous extract as a protective and therapeutic agent against epilepsy induced spatial learning deficits in pilocarpine model of temporal lobe epilepsy.

\section{Materials and Methods}

Experimental protocol: In this experimental study, sixty

Copyright (c) 2015, Zahedan University of Medical Sciences. This is an open-access article distributed under the terms of the Creative Commons Attribution-NonCommercial 4.0 International License (http://creativecommons.org/licenses/by-nc/4.0/) which permits copy and redistribute the material just in noncommercial usages, provided the original work is properly cited. 
Elahdadi-Salmani M et al.

Wistar rats (Pasteur Institute, Iran) weighing $200 \pm 20 \mathrm{~g}$ were employed and divided into 5 groups, each having 10 animals. 1-Control, 2-Coriandrum sativum L., 3-Pilocarpine induced epilepsy (Convulsion), 4- Convulsion followed by C. sativum, 5- C. sativum followed by convulsion. All experiments were done in accordance with the National Institute of Health Guide for the Care and Use of Laboratory Animals (NIH Publication No. 23-80, revised 1996) and were approved by the research ethical standards for the care and use of animals in Damghan University. Rats were kept 5 per cage in $23 \pm 1^{\circ} \mathrm{C}$ room temperature with normal 12-12 h light-dark cycle, and lights on at 07:00 am, and food and water ad libitum.

Pilocarpine induced convulsions: Rats were treated with lithium chloride and pilocarpine to induce temporal lobe seizures. Lithium chloride ( $3 \mathrm{mEq} / \mathrm{kg}$, i.p.) was administered $24 \mathrm{~h}$ prior to pilocarpine injection. Atropine ( $1 \mathrm{mg} /$ $\mathrm{kg}$, i.p.), a muscarinic cholinergic antagonist, was administered $30 \mathrm{~min}$ prior to pilocarpine injection $(30 \mathrm{mg} / \mathrm{kg}$, i.p.) to minimize the peripheral effects of the cholinergic action of pilocarpine (e.g., salivation, diarrhea). Onset of status epilepticus (SE) typically occurred within 30 to 50 min after pilocarpine injection and was determined when the animal displayed continuous, moderate to severe behavioral seizures characterized by forelimb clonus, rearing, and falling. SE was defined as continuous behavioral seizure activity lasting at least $30 \mathrm{~min}$. The severity of convulsions was evaluated using Racine's classification, and only those animals that were classified stage IV or V were included in the study. Sixty minutes after SE onset, diazepam (10 mg/kg, i.p.) was administered to control seizure activity and reduce mortality. To minimize the acute effects of seizures, epileptic rats were further monitored to ensure that no seizures had occurred $2 \mathrm{~h}$ before water maze experiments. Control rats were injected with the same drugs except atropine and pilocarpine (still received injections of lithium and diazepam (saline treatment)).

Preparation of coriander extract: $C$. sativums were purchased from a registered herbal medicine shop and identified and authenticated by a specialist in pharmacognosy in Damghan University. Dried leaves of coriander were ground to a fine powder. Ten grams of this powder was diluted using $50 \mathrm{~mL}$ of ethanol $80 \%$. This suspension was filtered by filter paper during $72 \mathrm{~h}$, and the extract was transferred to an open plate and kept for 14 days to achieve a concentrated form of the extract. C. sativum extract was given to rats for seven consecutive days (200 $\mathrm{mg} / \mathrm{kg}$; i.p.). The same volume of solvent (saline), were injected to control groups.

Water maze test: A circular tank $(140 \mathrm{~cm}$ in diameter, 60 $\mathrm{cm}$ high) filled with water at a temperature of $24 \pm 2^{\circ} \mathrm{C}$ to depth of $30 \mathrm{~cm}$, was used for the procedure. An escape invisible platform $(15 \mathrm{~cm}$ in diameter) was placed $2 \mathrm{~cm}$ below the water surface, midway between the center and rim of the pool in the same quadrant throughout the task with the spatial cues available around the pool room. One day before the behavioral testing, each animal was habituated for $1 \mathrm{~min}$ on platform to explore the pool. During the learning task, animals had to navigate the hidden platform, given four trials a day for 5 days, while the starting positions changed randomly over trials. Each trial began with the animal in the pool facing the sidewalls and ended either after $60 \mathrm{~s}$ of swimming or reaching the platform. The rat was then allowed to remain on the platform for $10 \mathrm{~s}$ after each trial. Two probe tasks were performed $24 \mathrm{~h}$ and one week after last day of learning trials with the platform removed from the pool. All of the learning and memory tasks were recorded with a CCD camera connected to a computer with Ethovision-XT tracking software (Noldus Company) designed for data acquisition and analysis. The parameters measured in learning and memory tasks, were the distance and the latency to escape onto the platform and velocity of swimming. In the probe task, total distance traveled during 60 s and the time swam to locate the platform area (platform location latency), where the platform had been located during the learning task, were measured. The proximity, average of the swimming distance from the center of platform location and number of crossings from target area were also considered. The results were analyzed as the individual mean of the four daily trials.

Drugs: Lithium chloride (cat, L4408) and pilocarpine (cat, P6503) from Sigma Aldrich were used in this research. Diazepam and Atropine were purchased from local drug market in Iran.

Statistical analysis: Results of the experiments in MWM (escape latencies, distance travelled, and swimming velocity) were analyzed using two-way ANOVA during acquisition days. Probe trials analysis using the following factors; platform location latency, total path length, swimming velocity, proximity and crossing were performed by oneway ANOVA. Post-hoc comparison of group means was performed with the tukey test. All of statistical tests were performed by SPSS-16 software. Data presented as mean \pm SEM. Minimum significant level was set at $\mathrm{P}<0.05$.

\section{Results}

C. sativum extract reversed epilepsy induced increase of latency: Statistical analysis employing two way ANOVA revealed a significant difference in days $\left(\mathrm{F}_{4,210}=\right.$ $45.45, \mathrm{P}=0.001, \mathrm{~N}=47)$ and also between groups $\left(\mathrm{F}_{4,210}=\right.$ 41.286, $\mathrm{P}=0.001, \mathrm{~N}=50)$, which was significant even in the intersection of days and groups $\left(\mathrm{F}_{16,210}=1.90, \mathrm{P}=0.02, \mathrm{~N}=\right.$ $50)$. There were prominent differences in the first $\left(\mathrm{F}_{4,210}=\right.$ $7.84, \mathrm{P}=0.001, \mathrm{~N}=47)$ and second $\left(\mathrm{F}_{4,210}=5.60, \mathrm{P}=0.001\right.$, $\mathrm{N}=47$ ) days between different groups. Statistical analysis showed an increase of latency in pilocarpine treated animals in the first $(\mathrm{P}=0.02)$ and second $(\mathrm{P}=0.001)$ days. C. sativum extract pretreatment, on the other hand, decreased the latency of platform locating in epileptic rats in the first $(\mathrm{P}=0.004)$ and second $(\mathrm{P}=0.05)$ days. Altogether, while epilepsy could delay the spatial latency to locate the platform, the $C$. sativum extract compensated this delay and even reversed that effect (Figure 1). 
Figure 1. Effect of Convulsion and C. sativum Extract on Learning Acquisition Latency

A

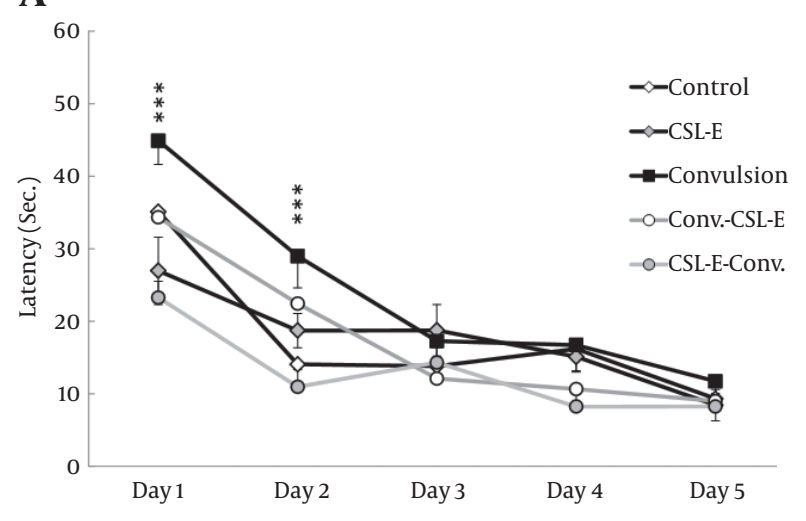

B

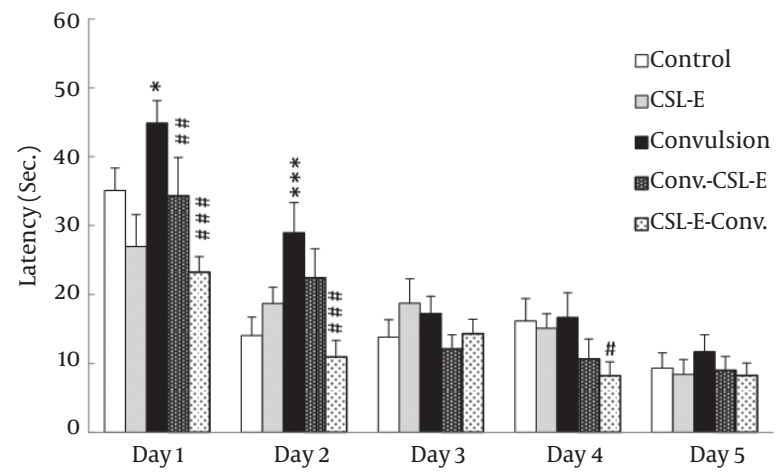

A. Latency to find the platform was changed due to convulsion and C. sativum extract treatment during first two days. B. Latency to find the platform was increased in convulsion group during first and second acquisition days. C. sativum extract treatment in the first and second day and pretreatment in the first day decreased the latency to previous level. Square show the difference between $C$. sativum extract and convulsion group. ${ }^{*} \mathrm{P}<0.05$; ${ }^{* *} \mathrm{P}<0.001$; \#\# $\mathrm{P}<0.01$; \#\#\# $\mathrm{P}<0.001$.

C. sativum extract reversed epilepsy induced increase of distance: Investigating the effect of C. sativum extract on acquisition of spatial learning; distance travelled in different groups using two-way ANOVA, showed a significant statistical difference over the days (day 1-5) of learning $\left(\mathrm{F}_{4,210}=29.33, \mathrm{P}=0.001\right)$ and also between groups $\left(\mathrm{F}_{4,210}=4.52, \mathrm{P}=0.002\right)$, but not significant in the intersection of days and groups $\left(\mathrm{F}_{16}, 2_{10}=1.24\right)$. Tukey post hoc operation showed group differences during the first $(\mathrm{P}<0.05)$ and second $(\mathrm{P}<0.01)$ days of learning paradigm (Figure 2).

While statistical analysis showed an increase of distance in pilocarpine treated animals in the first $(P=0.01)$ and second $(\mathrm{P}=0.01)$ days, $C$. sativum extract pretreatment decreased the distance to find the platform in epileptic rats, comparing to convulsion group, in the first $(\mathrm{P}=0.01)$ and second ( $\mathrm{P}=0.001)$ days. Meanwhile, swimming velocity did not change significantly over days or between groups.
Figure 2. Effect of Convulsion and C. sativum Extract on Distance

A

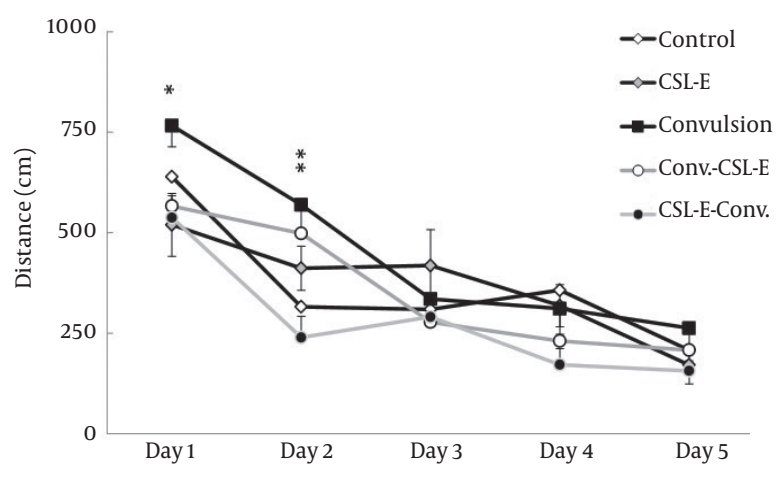

B

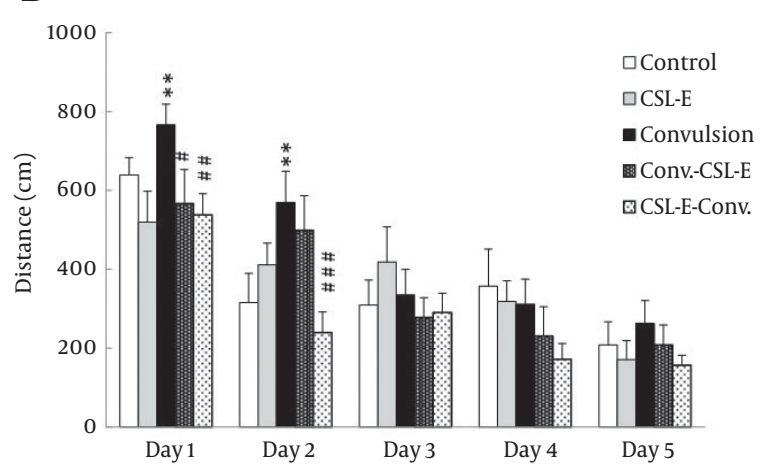

A. Distance to find the platform was changed due to convulsion and C. sativum extract treatment in the first and second days. B. Distance to find the platform was increased in convulsion group during first and second acquisition days. C. sativum extract treatment in the first and second day and pretreatment in the first day decreased the latency to control level. Asterisks show the differences between each group and control, while square show the difference between $C$. sativum extract and convulsion group. ${ }^{*} \mathrm{P}<0.05$; ${ }^{* *} \mathrm{P}<0.01$; \# $\mathrm{P}<0.05$; \#\# $\mathrm{P}<0.01$; \#\#\# $\mathrm{P}<0.001$.

C. sativum extract reversed epilepsy induced memory impairment: One day after learning acquisition, rats were allotted to retrieval (probe) test in MWM, which showed significant difference in navigating the platform area $\left(\mathrm{F}_{4,42}=2.82, \mathrm{P}=0.03\right)$ by using one way ANOVA test. Post hoc test indicated no difference in the first session of probe trial on $24 \mathrm{~h}$ after acquisition, but there was an increase $(\mathrm{P}<0.05)$ in platform location latency of convulsion group, one week later, compared to respective control which could not be ameliorated after $C$. sativum pretreatment or treatment and even increase $(P<0.05)$ more than convulsion latency (Figure 3 ). There was no statistical difference in total distance travelled during 60 seconds of swimming $\left(\mathrm{F}_{4,42}=1.59\right)$ along with swimming velocity $\left(\mathrm{F}_{4,42}=1.54\right)$ between different groups.

Proximity (the distance swam from the platform) in probe trial was analyzed using one way ANOVA, revealing a prominent difference between groups in second probe 
Figure 3. Effect of Convulsion and C. sativum Extract on Probe Trial

A

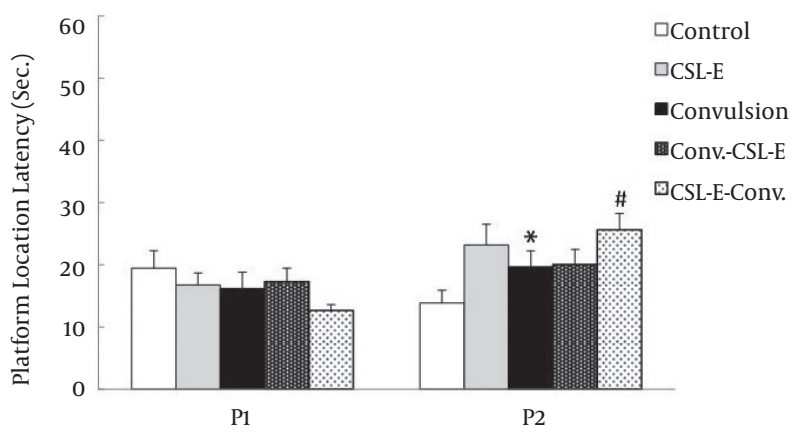

B

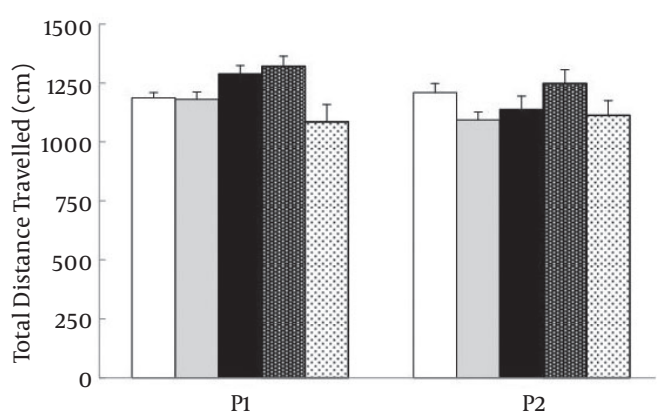

A. Platform location latency was increased in convulsion group during the second week probe trial and C. sativum extract pretreatment even increased the latency more than Convulsion group. B. there was no difference in total distance travelled in the first and second week of probe trial. Asterisks show the differences between each group and control, while square show the difference between $C$. sativum extract and convulsion group. ${ }^{*} \mathrm{P}<0.05 ; \# \mathrm{P}<0.05$.

session, one week later $\left(\mathrm{F}_{4,42}=4.61, \mathrm{P}=0.004\right)$. Tukey posthoc test showed an increase in the distance from target location in convulsion group $(\mathrm{P}<0.01)$ compared with control. This increase was reversed by $C$. sativum extract pretreatment $(\mathrm{P}<0.05)$ and treatment $(\mathrm{P}<0.01)$ groups, thereafter. Crossing is the other important measure of probe trial memory test which showed a significant difference $\left(\mathrm{F}_{4,42}=3.16, \mathrm{P}=0.02\right)$ in the second probe session, one week later. The tukey post hoc test showed a decrease in the crossing from target area $(\mathrm{P}<0.01)$, which was not compensated by C. sativum extract pretreatment or treatment (Figure 4).

\section{Discussion}

The present study investigated the pretreatment and treatment effect of $C$. sativum extract on spatial learning acquisition and memory retrieval deficits induced by pilocarpine epilepsy in adult male Wistar rats. The results of the study showed that $C$. sativum extract reversed the transient increase of latency and distance of acquisition water maze learning of epileptic rats. Further, the extract reversed some attributes of the memory retrieval of delayed impairment due to pilocarpine application.

Previous studies have reported hippocampus dependent spatial memory impairment in pilocarpine-treated
Figure 4. Effect of Convulsion and C. sativum Extract on Probe Trial

A

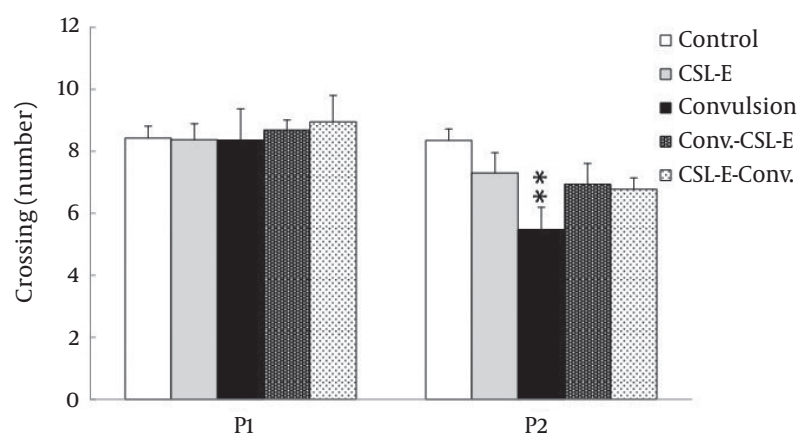

B

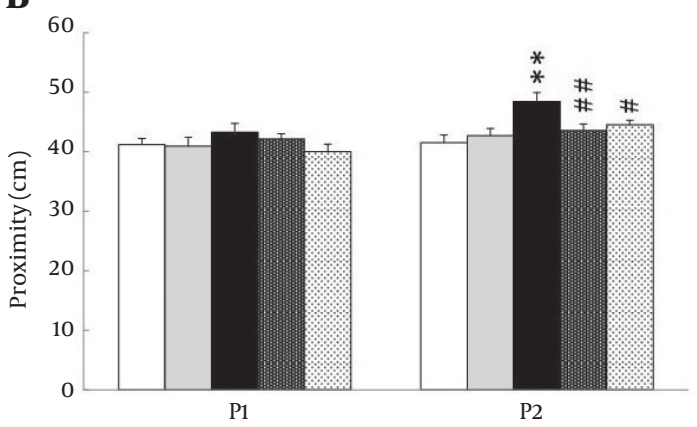

A. Crossing number was decreased in convulsion group during the second week probe trial. B. Proximity was increased in convulsion group during the second week probe trial and C. sativum extract treatment and pretreatment decreased the proximity to previous level. Asterisks show the differences between each group and control, while square show the difference between $C$. sativum extract and convulsion group. ${ }^{* *} \mathrm{P}<0.001$ $\# \mathrm{P}<0.05$; \#\# $\mathrm{P}<0.01$.

rats as assessed in the MWM $(14,15,27)$. Our data showed a reduction of learning acquisition; however it was only a transient reduction in water maze task. One study demonstrated a prominent reduction of memory in Sprague dawley but not Wistar rats (28), which shows strain dependency. Another study revealed that memory impairment is more probably related to lesion comorbidity rather than epilepsy itself (28).

Retrieval data demonstrated a delayed impairment, one week later, on the time of probable structural lesion. Although the atropine used in this study may also affect memory, but that is only in chronic treatment, not the single dose, and requires enhanced drug uptake by the central cholinergic receptors (29). Oxygen-free radicals have been shown to be neurotoxic, structural change and circuit derangement. This may lead to degenerative diseases as well as epilepsy.

The epilepsy model induced by pilocarpine has been extensively studied, because it produces spontaneous recurrent seizures, which may explain many of the neurochemical changes in oxidative stress seen in temporal lobe epilepsy in humans. The histopathological changes observed in the hippocampus produces many of these changes observed in humans, including neuronal loss and 
gliosis, also allowing for the evaluation of the presence of neuronal damage after seizures $(30,31)$. But, lack of epilepsy effect on memory, one day following learning, indicates that memory retrieval in epileptic condition requires time dependent development of epileptic memory network and distinct mechanisms of learning and memory in the brain. We demonstrated that $C$. sativum extract was able to reverse the transient learning deficit induced by pilocarpine. Further, C. sativum extract reversed memory impairment, one week later, in proximity and crossing measures, but not the latency. $C$. sativum extract as rich antioxidant constituents may reduce the oxidative injuries of convulsive experiences. As previously shown, oxidative damage can have a profound effect on learning and memory and epilepsy as such impairs learning and memory (32).

C. sativum extract, by promotion of antioxidant level, probably via its antioxidant constituents like quercetin, prevents the oxidative damage, which might be the basis for learning and memory compensation in C. sativum extract treated epileptic rats (33). Results from the present study are in line with the literature data regarding the neuroprotective effects of $C$. sativum extract in Alzheimer model induced memory loss (26). These results suggest a possible direct and/or indirect interaction between the cholinergic system (34) and the antioxidant defense systems in the development of neuronal injury caused by seizures (32).

In summary, the present findings suggest that pilocarpine seizures induced a transient impairment in the spatial learning and a delayed impairment of memory retrieval. On the other hand, C. sativum extract exerted neuroprotective effects against these learning and memory deficits. Therefore, the therapeutic potential of C. sativum extract in the management of memory impairments of epileptic patients may be of great interest. However, further studies should be conducted to fully clarify the mechanism of neuroprotective action of C. sativum extract during the establishment of seizures.

\section{Acknowledgements}

This work was financially supported by the institute of biological sciences, Damghan University that has been approved by the doctor Mahmoud Elahdadi Salmani at Damghan University with project code 91/Bio/109/204. Authors declare no conflict of interests.

\section{Authors' Contributions}

All authors had equal role in design, work, statistical analysis and manuscript writing.

\section{Conflict of Interest}

The authors declare no conflict of interest.

\section{Funding/Support}

Damghan University has been supported this study.

\section{References}

1. Baxendale S. Amnesia in temporal lobectomy patients: historical perspective and review. Seizure.1998;7(1):15-24

2. Baxendale SA. The hippocampus: functional and structural correlations. Seizure. 1995;4(2):105-17.

3. Aldenkamp A, Arends J. The relative influence of epileptic EEG discharges, short nonconvulsive seizures, and type of epilepsy on cognitive function. Epilepsia. 2004;45(1):54-63.

4. Dodrill CB. Neuropsychological effects of seizures. Epilepsy Behav. 2004;5 Suppl 1:S21-4.

5. Helmstaedter C, Kurthen M. Memory and epilepsy: characteristics, course, and influence of drugs and surgery. Curr Opin Neurol. 2001;14(2):211-6.

6. Helmstaedter C, Kurthen M, Lux S, Reuber M, Elger CE. Chronic epilepsy and cognition: a longitudinal study in temporal lobe epilepsy. Ann Neurol. 2003;54(4):425-32.

7. Soria C, Callu D, Viguier D, El Sabbagh S, Bulteau C, Laroussinie F, et al. Parental report of cognitive difficulties, quality of life and rehabilitation in children with epilepsy or treated for brain tumour. Dev Neurorehabil. 2008;11(4):268-75.

8. Aldenkamp AP, Bodde N. Behaviour, cognition and epilepsy. Acta Neurol Scand Suppl. 2005;182:19-25.

9. Elger CE, Helmstaedter C, Kurthen M. Chronic epilepsy and cognition. Lancet Neurol. 2004;3(11):663-72.

10. Motamedi G, Meador K. Epilepsy and cognition. Epilepsy Behav. 2003;4 Suppl 2:S25-38.

11. Kohr G. NMDA receptor antagonists: tools in neuroscience with promise for treating CNS pathologies. J Physiol. 2007;581(Pt1):1-2.

12. Hermann BP, Seidenberg M, Schoenfeld J, Davies K. Neuropsychological characteristics of the syndrome of mesial temporal lobe epilepsy. Arch Neurol.1997;54(4):369-76.

13. Meador KJ, Loring DW, Ray PG, Murro AM, King DW, Perrine KR, et al. Differential cognitive and behavioral effects of carbamazepine and lamotrigine. Neurology. 2001;56(9):1177-82.

14. Chauviere L, Rafrafi N, Thinus-Blanc C, Bartolomei F, Esclapez M, Bernard C. Early deficits in spatial memory and theta rhythm in experimental temporal lobe epilepsy.J Neurosci. 2009;29(17):5402-10.

15. Frisch C, Kudin AP, Elger CE, Kunz WS, Helmstaedter C. Amelioration of water maze performance deficits by topiramate applied during pilocarpine-induced status epilepticus is negatively dose-dependent. Epilepsy Res. 2007;73(2):173-80.

16. Zhang Y, Cai GE, Yang Q, Lu QC, Li ST, Ju G. Time-dependent changes in learning ability and induction of long-term potentiation in the lithium-pilocarpine-induced epileptic mouse model. Epilepsy Behav. 2010;17(4):448-54.

17. Szyndler J, Piechal A, Blecharz-Klin K, Skorzewska A, Maciejak P, Walkowiak J, et al. Effect of kindled seizures on rat behavior in water Morris maze test and amino acid concentrations in brain structures. Pharmacol Rep. 2006;58(1):75-82.

18. Mehla J, Reeta KH, Gupta P, Gupta YK. Protective effect of curcumin against seizures and cognitive impairment in a pentylenetetrazole-kindled epileptic rat model. Life Sci. 2010;87(19-22):596-603.

19. Gayoso MJ, Primo C, al-Majdalawi A, Fernandez JM, Garrosa M, Iniguez $\mathrm{C}$. Brain lesions and water-maze learning deficits after systemic administration of kainic acid to adult rats. Brain Res. 1994;653(1-2):92-100.

20. Bhuiyan MI, Begum J, Sultana M. Chemical composition of leaf and seed essential oil of Coriandrum sativum L. from Bangladesh. Bangladesh J Pharmacol. 2009;4(2).

21. Gray AM, Flatt PR. Insulin-releasing and insulin-like activity of the traditional anti-diabetic plant Coriandrum sativum (coriander). BrJ Nutr. 1999;81(3):203-9.

22. Jabeen Q, Bashir S, Lyoussi B, Gilani AH. Coriander fruit exhibits gut modulatory, blood pressure lowering and diuretic activities. JEthnopharmacol. 2009;122(1):123-30.

23. Duke JA, Bogenschutz-Godwin M, duCelliar J. Handbook of medicinal herbs.London: CRC Press; 2002

24. Bhattachacharjee SK. Handbook of medicinal plants.Jaipur: Aavishkar Publishers; 2001.

25. Mani V, Parle M. Memory-enhancing activity of Coriandrum sativum in rats. Pharmacologyonline. 2009;2:827-39.

26. Mani V, Parle M, Ramasamy K, Abdul Majeed AB. Reversal of mem- 
ory deficits by Coriandrum sativum leaves in mice. J Sci Food Agric. 2011;91(1):186-92.

27. Detour J, Schroeder H, Desor D, Nehlig A. A 5-month period of epilepsy impairs spatial memory, decreases anxiety, but spares object recognition in the lithium-pilocarpine model in adult rats. Epilepsia. 2005;46(4):499-508.

28. Inostroza M, Cid E, Brotons-Mas J, Gal B, Aivar P, Uzcategui YG, et al. Hippocampal-dependent spatial memory in the water maze is preserved in an experimental model of temporal lobe epilepsy in rats. PLoS One. 2011;6(7).

29. Dhume RA, Nagwekar MD, Noronha A, Varde MR, Mascarenhas JF. Four-arm radial open maze (FAROM) as a tool for assessing the effect of atropine in spatial memory of the rats. Indian J Physiol Pharmacol.1989;33(1):1-9.

30. Garcia-Cairasco N, Wakamatsu H, Oliveira JA, Gomes EL, Del Bel EA, Mello LE. Neuroethological and morphological (Neo-Timm staining) correlates of limbic recruitment during the development of audiogenic kindling in seizure susceptible Wistar rats. Epilepsy Res. 1996;26(1):177-92.

31. Peredery O, Persinger MA, Blomme C, Parker G. Absence of maternal behavior in rats with lithium/pilocarpine seizure-induced brain damage: support of MacLean's triune brain theory. Physiol Behav. 1992;52(4):665-71.

32. Tome Ada R, Feitosa CM, Freitas RM. Neuronal damage and memory deficits after seizures are reversed by ascorbic acid? Arq Neuropsiquiatr. 2010;68(4):579-85.

33. Cioanca O, Hritcu L, Mihasan M, Hancianu M. Cognitive-enhancing and antioxidant activities of inhaled coriander volatile oil in amyloid beta(1-42) rat model of Alzheimer's disease. Physiol Behav. 2013;120:193-202.

34. Joshi H, Parle M. Cholinergic basis of memory-strengthening effect of Foeniculum vulgare Linn. J Med Food. 2006;9(3):413-7. 